Palavras chave: Legislação Ambiental Gestão Ambiental Instrumentos ambientais Brasil

Histórico: Recebido 04/04/2013 Aceito 28/04/2015

Keyworks: Environmental Legislation Environmental Management Environmental instruments Environmental Compensation

Correspondence: barros_eva@yahoo.com.br
Eva Costa de Barros', Luis Antonio Coimbra Borges', Maria das Graças Paula', Flávia Luciana Naves Mafra'

\section{O INSTRUMENTO DE COMPENSAÇÃO AMBIENTAL NO BRASIL E NO ESTADO DE MINAS GERAIS}

RESUMO: A compensação ambiental para empreendimentos causadores de significativo impacto ambiental é um instrumento instituído pelo artigo 36 da lei $n^{\circ}$ 9.985/2000. O objetivo do trabalho foi descrever, analisar a legislação ambiental pertinente ao instrumento de Compensação Ambiental no Brasil e apresentar o estado de Minas Gerais como um estudo de caso. Para isto adotou-se as técnicas de pesquisa bibliográfica e pesquisa documental. $O$ resultado demonstrou que a compensação ambiental aumentou no estado de Minas Gerais e pode ser uma ferramenta importante para auxiliar na conservação ambiental por meio das Unidades de Conservação.

\section{THE INSTRUMENT OF ENVIRONMENTAL COMPENSATION IN BRAZIL AND IN THE STATE OF MINAS GERAIS}

ABSTRACT: Compensation for environmental projects that cause significant environmental impact is an instrument established by Article 36 of Law No. $9.985 / 2000$. The objective of this study was to describe and analyze relevant environmental legislation to the Environmental Compensation instrument in Brazil and use the state of Minas Gerais as a case study. For this we adopted the techniques of bibliographic and documentary research. The result showed that environmental compensation increased in the state of Minas Gerais and can be an important tool to help in environmental conservation through protected areas. 


\section{INTRODUÇÃO}

A Lei Federal $n^{\circ} 6.938 / 81$, que dispõe sobre a Política Nacional de Meio Ambiente (PNMA) é um importante marco para a proteção ambiental no Brasil, instituiu um tratamento harmônico para a matéria que se encontrava esparsa e apresenta uma estrutura com conceitos, objetivos, princípios e instrumentos para gestão ambiental (JUCOVSKY, 20 I0; ANTUNES, 2005).

APNMA elenca em seu art. $8^{\circ}$ treze instrumentos legais e institucionais para alcançar os seus objetivos, destacando-se para este trabalho três deles: Avaliação de Impacto Ambiental, Licenciamento Ambiental e Espaços Territoriais especialmente protegidos pelo Poder Público. Os três instrumentos possuem relação direta com a compensação ambiental, que visa a compensar os impactos irreversíveis dos empreendimentos potencialmente poluidores por meio de apoio à criação, regularização fundiária, pesquisas científicas e elaboração de planos de manejo das Unidades de Conservação no Brasil e estados.

O Brasil possui uma lei federal que trata especificamente de Unidades de Conservação, a Lei $\mathrm{n}^{\circ}$ 9.985/2000, que instituiu o Sistema Nacional de Unidades de Conservação (SNUC). O SNUC apresenta a exigência da compensação ambiental em seu artigo 36.

Estudos que analisam o procedimento da compensação ambiental no Brasil, especialmente em MG, não são disponíveis na literatura científica, fazendo com que esta ferramenta não seja conhecida pela sociedade. Portanto, objetiva-se neste trabalho descrever e analisar a legislação ambiental pertinente ao instrumento de Compensação Ambiental no Brasil e apresentar o estado de Minas Gerais como um estudo de caso.

\section{MATERIAL E MÉTODOS}

$\mathrm{Na}$ primeira etapa foram aplicadas as técnicas de pesquisa bibliográfica e pesquisa documental para a descrição e discussão da evolução da legislação ambiental (GIL, 1999;2002). Na segunda parte, utilizou-se a estatística descritiva para a análise quantitativa dos dados referentes à compensação ambiental no estado de Minas Gerais desde a publicação da lei do SNUC até o ano de 2012. Os dados utilizados foram disponibilizados pela Gerência de Compensação Ambiental do Instituto Estadual de Florestas (GCA/IEF) do estado de Minas Gerais.

\section{RESULTADOS E DISCUSSÃO}

\section{Histórico da Compensação Ambiental}

A legislação ambiental brasileira apresenta cinco modalidades de compensação ambiental normatizadas por lei: Compensação pela implantação de empreendimentos causadores de significativo impacto ambiental, art. 36 da Lei Federal $n^{\circ}$ 9.3985/2000; Compensação por dano ambiental irreversível, art. I4, § $1^{\circ}$, da Lei n ${ }^{\circ}$ 6.938/198I; Compensação pela supressão de Áreas de Preservação Permanente (APP); Compensação de Reserva Legal (RL), Código Florestal, art. 4I, 48, 50, 66 da Lei Federal n 12.65I/2012; Compensação pela supressão de Mata Atlântica, Lei Federal n I I.428/2006.

A compensação ambiental é exigida antes da instalação de empreendimentos causadores de significativo impacto ambiental, inicialmente normatizada pela Resolução do CONAMA n 10/1987, atualmente revogada. A resolução previa no seu art. $1^{\circ}$ que as obras de grande porte assim consideradas pelo órgão licenciador, fundamentada no Relatório de Impacto Ambiental (RIMA), teria como um dos seus requesitos prévios a implantação de uma Estação Ecológica pela entidade ou empresa responsável pelo empreendimento, preferencialmente junto a área que sofrerá o impacto. $\bigcirc$ empreendedor era obrigado a realizar um investimento nesta nova área e nas benfeitorias, conforme o art. $2^{\circ}$ e não poderia ser inferior a $0,5 \%$ (meio por cento) dos custos totais previstos para a implantação do empreendimento, proporcional ao dano ambiental a ressarcir.

Após a sua revogação, entrou em vigor a Resolução CONAMA n 2/1996, também revogada, que ampliava a forma de compensação ambiental. Os empreendedores poderiam aplicar o recurso da compensação em outras formas de unidade de conservação públicas, tal como as unidades de conservação de proteção integral (uso indireto), e não só em estações ecológicas como era anteriormente.

Para Machado (20II), a compensação ambiental é uma norma muito importante, pois é destinada a instituir a Unidade de Conservação, bem como mantê-la. A criação das UCs por meio da resolução CONAMA 2/1996 e a consolidação e integração das mesmas ao corpo mais amplo de normas por meio da Lei Federal 9.985/2000 pode fortalecer esta modalidade de compensação. 
A Lei Federal $n^{\circ} 9.985 / 2000$, que instituiu - Sistema Nacional de Unidades de Conservação (SNUC), trata da temática no art. 36. O Decreto Federal $n^{\circ} 4.320 / 2002$ e o Decreto Federal $n^{\circ}$ 5.566/2005, regulamentaram artigos da lei supracitada. Os atos normativos baixados pelo Instituto Brasileiro de Meio Ambiente e Recursos Naturais (IBAMA), tiveram como objetivo a criação e a implantação da Câmara de Compensação Ambiental, conforme a Portaria $n^{\circ}$ 7/2004 e Portaria 44/2004, responsáveis pela gestão da compensação ambiental. Considerando a importância, a Instrução Normativa IN-47/2004, ordenou às ações internas e estabeleceu os procedimentos para a Compensação Ambiental no âmbito do IBAMA.

$O$ art. 36 da Lei Federal $n^{\circ} 9.985 / 2000$, estabelece que os recursos arrecadados devem ser destinados às unidades de conservação existentes na área, federais, estaduais ou municipais, independentemente do órgão licenciador ser federal, estadual ou municipal.

O $2^{\circ}$ do mesmo artigo prevê que a determinação das unidades de conservação a serem beneficiadas ocorrerá através da decisão do órgão ambiental licenciador levando em consideração as propostas apresentadas no EIA/RIMA e ouvido o empreendedor, podendo até mesmo ser contemplada a criação de novas unidades de conservação.

As Unidades de Conservação destinatárias da compensação podem ser diferentes, conforme $\circ$ enquadramento do caso ou do caput do art. 36 ou do $\S 3^{\circ}$ do mesmo artigo. No caso de empreendimentos que não afetam diretamente Unidade de Conservação específica ou sua zona de amortecimento, a compensação ambiental será aplicada somente nas Unidades de Proteção Integral. E para empreendimentos que irão afetar Unidade de Conservação específica ou sua zona de amortecimento aplica-se $\circ \S 3^{\circ}$ do art. 36 em que a Unidade afetada, mesmo não pertencente ao Grupo de Proteção Integral, deverá ser beneficiada pela compensação.

Machado (20II) apresenta uma crítica ao instrumento de compensação ambiental no sentido de que o pagamento monetário não alcança os demais campos que são afetados com o licenciamento do empreendimento, como a poluição das águas, da atmosfera e do solo - por meio dos rejeitos e agrotóxicos, uma vez que o valor pago pelo empreendedor será totalmente destinado para as unidades de conservação.

A compensação ambiental sempre foi alvo de muitas críticas e questionamentos por parte dos empreendedores (BESSA, 2008). A Ação de Inconstitucionalidade 3.379-6 (ADIn) ajuizada pela Confederação Nacional da Indústria, pode ser destacada como exemplo. $O$ seu principal questionamento era $\circ$ percentual mínimo para $\circ$ cálculo do valor da compensação ambiental dos empreendimentos causadores de significativo impacto ambiental. Em 2008, - Supremo Tribunal Federal, no julgamento desta ADIn julgou inconstitucional a utilização de um percentual mínimo na forma do cálculo do valor da cobrança da compensação ambiental, sendo necessária a observância de critérios de gradação dos impactos ambientais. A fim de sanar a problemática do cálculo, foi publicado - Decreto Federal n 6.848, de 14 de maio de 2009, alterando e acrescentado dispositivos no Decreto Federal $n^{\circ} 4.340$, de 22 de agosto de 2002, com o objetivo de regulamentar a compensação ambiental.

Com nova redação, 0 art. 31 do Decreto no 4.340/2002, agora como Decreto 6.848/09, determina que para o cálculo do grau de impacto ambiental será levado em consideração o Estudo de Impacto Ambiental e - Relatório de Impacto Ambiental (EIA/RIMA), no que se cita aos impactos negativos para o meio ambiente. Para o cálculo, o impacto causado será levado em consideração apenas uma vez e deverá conter os indicadores do impacto gerado pelo empreendimento e das características do ambiente a ser impactado, não sendo incluídos no cálculo os investimentos referentes aos planos, projetos e programas exigidos no procedimento de licenciamento ambiental para mitigação de impactos. A compensação ambiental poderá incidir sobre cada trecho em que a licença for emitida. Este tipo de modelagem é muito útil porque emite uma certa quantificação de processos e resultados que de outra forma ficariam muito subjetivos e indeterminados.

A metodologia de cálculo da compensação ambiental está detalhada no art. $3 \mathrm{I}-\mathrm{A}$, do Decreto $\mathrm{n}^{\circ}$ $6.848 / 09$. O valor da compensação será calculado pela multiplicação do Valor de Referência pelo Grau de Impacto, de acordo com a equação I, sendo $C A=$ Valor da Compensação Ambiental; VR = Valor de Referência; e $\mathrm{Gl}=$ Grau de Impacto nos ecossistemas.

$\mathrm{CA}=\mathrm{VR} \times \mathrm{Gl}$

O Valor de Referência é o somatório dos investimentos necessários para implantação 
do empreendimento. Deste valor, exclui-se os investimentos exigidos no procedimento de licenciamento ambiental para mitigação de impactos causados pelo empreendimento.

O Grau de Impacto é detalhado na legislação, conforme o art. 3I-A. O valor destinado a compensação ambiental obedece um mínimo de zero e um máximo de 0,5\%. O EIA/RIMA do empreendimento deverá conter as informações essenciais para o cálculo do Valor de Referência e deverá ser apresentado ao órgão ambiental licenciador antes do empreendedor receber a licença de instalação.

O Grau de Impacto (GI) tem um tratamento especial no anexo do decreto, composto por outra fórmula em que envolve o Impacto sobre a Biodiversidade (ISB), o Comprometimento de Área Prioritária (CAP) e a Influência em Unidade de Conservação (IUC).

O pagamento da compensação ambiental deverá ocorrer no período inicial do licenciamento, ou seja, durante a fase de Licença Prévia ou no máximo até a fase de Licença de Instalação. Machado (20 I I), salienta que o valor de referência deverá ser apresentado ao órgão licenciador de maneira fidedigna, ao Ministério Público, a ONG interessada ou a qualquer cidadão que solicite esclarecimentos.

A gestão da compensação ambiental foi prevista na redação do artigo 32 do Decreto Federal 4.340/2002 em que apresenta a Câmara de Compensação Ambiental e sua instituição no âmbito do Ministério do Meio Ambiente, e posteriormente, é complementada pelo Decreto Federal no 6.848/2009 e tem como finalidade: estabelecer prioridades e diretrizes para aplicação da compensação ambiental; avaliar e auditar, periodicamente, a metodologia e os procedimentos de cálculo da compensação ambiental, de acordo com estudos ambientais realizados e percentuais definidos, propor diretrizes necessárias para agilizar a regularização fundiária das unidades de conservação; e estabelecer diretrizes para elaboração e implantação dos planos de manejo das unidades de conservação.

O mesmo decreto apresenta como será a aplicação dos recursos de compensação ambiental, regulamentandooartigo 36 daLeiFederal ${ }^{\circ} 9.985 / 2000$, e estabelece a ordem de prioridade que deverá ser obedecida: regularização fundiária e demarcação das terras; elaboração, revisão ou implantação de plano de manejo; aquisição de bens e serviços necessários à implantação, gestão, monitoramento e proteção da unidade, compreendendo sua área de amortecimento desenvolvimento de estudos necessários à criação de nova unidade de conservação; desenvolvimento de pesquisas necessárias para o manejo da unidade de conservação e área de amortecimento (BRASIL, 2002).

A Compensação Ambiental no âmbito estadual no que tange a matéria possui caráter suplementar. O Decreto Federal $n^{\circ} 6.848 / 2009$, alterou alguns dispositivos do Decreto Federal no 4.340/2002, implicando, portanto, em modificações na legislação mineira, culminando na edição do Decreto Estadual $n^{\circ}$ 45. I75/2009.

O Decreto Estadual $n^{\circ} 45.175 / 2009$ tem como objetivo estabelecer a metodologia de gradação de impactos ambientais e procedimentos para fixação e aplicação da compensação ambiental. O Decreto apresenta algumas definições como o Plano Operativo Anual (POA), instrumento de planejamento com metas para cada uma das prioridades dispostas no art. 33 do Decreto Federal $n^{\circ} 4.340 / 2002$, elaborado pelo Instituto Estadual de Florestas (IEF), através da Gerência de Compensação Ambiental (GECAM), e aprovado pela Câmara de Proteção à Biodiversidade e de Áreas Protegidas do Conselho Estadual de Política Ambiental (CPB-COPAM) e leva em consideração as diretrizes estratégicas e de gestão das Unidades de Conservação do Estado (MINAS GERAIS, 2009).

No estado de Minas Gerais o empreendedor que necessita realizar a Compensação Ambiental deve assinar um Termo de Compromisso, que é um instrumento com força de título executivo extrajudicial, firmado entre empreendedor e órgãos gestores das Unidades de Conservação beneficiárias dos recursos advindos do respectivo empreendimento em que são estabelecidos obrigações, prazos e demais informações relevantes para a execução das medidas de compensação ambiental aprovadas pela CPB-COPAM.

A incidência da compensação ambiental é uma condicionante do licenciamento ambiental. A definição da compensação ambiental é competência do IBAMA (nível federal) e da Unidade Regional Colegiada do Conselho Estadual de Política Ambiental (URC-COPAM), com base no parecer único da Superintendência Regional de Meio Ambiente e Desenvolvimento Sustentável da Secretaria de Estado de Meio Ambiente e Desenvolvimento Sustentável (SUPRAM-SEMAD) no estado de MG. O 
parecer da SUPRAM-SEMAD apresentará as justificativas que permitirão a identificação do empreendimento como causador de significativo impacto ambiental e as suas respectivas classes conforme a Deliberação Normativa do COPAM 74/2004.

Em alguns casos pode haver a celebração de convênio com os municípios e o licenciamento de empreendimentos classificados em 3 e 4 podem ficar sob responsabilidade municipal. Ou seja, esta classificação relaciona o porte e o potencial poluidor do empreendimento.

O CODEMA deverá destinar os recursos da compensação ambiental conforme os termos das diretrizes do POA e aprovado pela CPB-COPAM. A ressalva que dever ser estabelecida é que o CODEMA pode sugerir em seu parecer a destinação do recurso, conforme o respaldo na Lei Complementar I40/20 I I.

Os empreendimentos considerados de significativo impacto ambiental, licenciados antes da Lei Federal $n^{\circ} 9.985 / 2000$, conforme o art.5० $\S 1^{\circ}$ do Decreto Estadual n० 45.175/09, que não possuirem a compensação ambiental delimitada na fase de licença prévia deverão cumprir a condicionante determinada na fase de licenciamento, de forma corretiva ou em revalidação do licenciamento

A fixação da compensação ambiental e sua aplicação é de competência exclusiva da CBP-COPAM, observado 0 inciso $X I$ do art. 21 do Decreto $n^{\circ}$ $44.316 / 2006$ e caberá ao IEF-GECAM, órgão de apoio à CPB-COPAM, a instrução do processo de cumprimento da compensação ambiental.

A apuração do valor a ser pago pelo empreendedor será calculado com base nas planilhas encaminhadas pela SUPRAM e CODEMA e a sugestão de aplicação do recurso nos termos do POA.

O valor de compensação ambiental será calculado, conforme metodologia de cálculo da compensação ambiental exigido pelo Decreto Federal 6.848/09. O Papel do empreendedor após - estabelecimento da condicionante relativa à compensação ambiental pela URC ou CODEMA consiste em procurar o IEF-GECAM para o seu cumprimento e apresentar planilhas detalhadas do Valor de Referência do empreendimento. A compensação ambiental fixada pela CPB-COPAM será consubstanciada em Termo de Compromisso de Compensação Ambiental e deverá ser firmada no prazo máximo de sessenta dias, a contar da publicação da decisão da CPB-COPAM.

As áreas beneficiárias da compensação ambiental, conforme o Decreto Estadual $n^{\circ}$ 45. I75/2009, no art. 17 define o procedimento que deverá ser adotado quando o empreendimento afetar uma unidade de conservação federal, estadual ou municipal ou sua zona de amortecimento. A aplicação dos recursos segue uma lista de prioridades estabelecidas pelo IEF, no entanto, as UC diretamente afetadas terão preferência para serem beneficiadas com os recursos provenientes da compensação ambiental.

\section{A Compensação Ambiental aplicada no estado de Minas Gerais}

Os recursos financeiros da compensação ambiental, por expressa disposição legal, destinam-se a apoiar a implantação, manutenção e, ou criação de Unidades de Conservação pertencentes ao Grupo de Proteção Integral. A exceção ocorrerá nos casos de Unidade(s) de Conservação afetada(s) diretamente pelos impactos de empreendimentos, $\S 3^{\circ}$ do art. $36 \mathrm{da}$ Lei Federal 9.985/2000 e art. $9^{\circ}$, inc. I da Resolução do CONAMA 37I/2006, em que a destinação de recurso é obrigatória à Unidade diretamente afetada. $\mathrm{O}$ art. $\mathrm{I}^{\circ}, \S$ $1^{\circ}$, da Resolução CONAMA 371/2006 esclarece que só poderão receber recursos da compensação ambiental as Unidades de Conservação inscritas no Cadastro Nacional de Unidades de Conservação (CNUC).

O Decreto Federal $n^{\circ} 4.340 / 2002$ possibilitou que os estados atuassem na compensação ambiental, e o primeiro processo do estado de MG ocorreu no ano de 2004. Houve, portanto, um periodo de defasagem de quatro anos após a criação do SNUC para a primeira compensação no estado de MG ser efetivada. De 2004 a 2012 alguns processos de compensação ambiental não foram julgados, sendo que o IEF reuniu uma força tarefa para julgamento dos passivos (processos não julgados) nos anos seguintes. Dos processos julgados após a implementação da Lei n 9.985/2000 até o fim de 2012, foram arrecadados como compensação ambiental no estado de Minas Gerais a quantia de R\$176.885. I 78,95. Estes dados foram sistematizados pelos autores após pesquisa realizada no banco de dados do IEF, na Cidade Administrativa, Belo Horizonte, MG.

$\mathrm{Na}$ distribuição dos recursos arrecadados desde 2004 (FIGURA I) nota-se o aumento dos valores da 


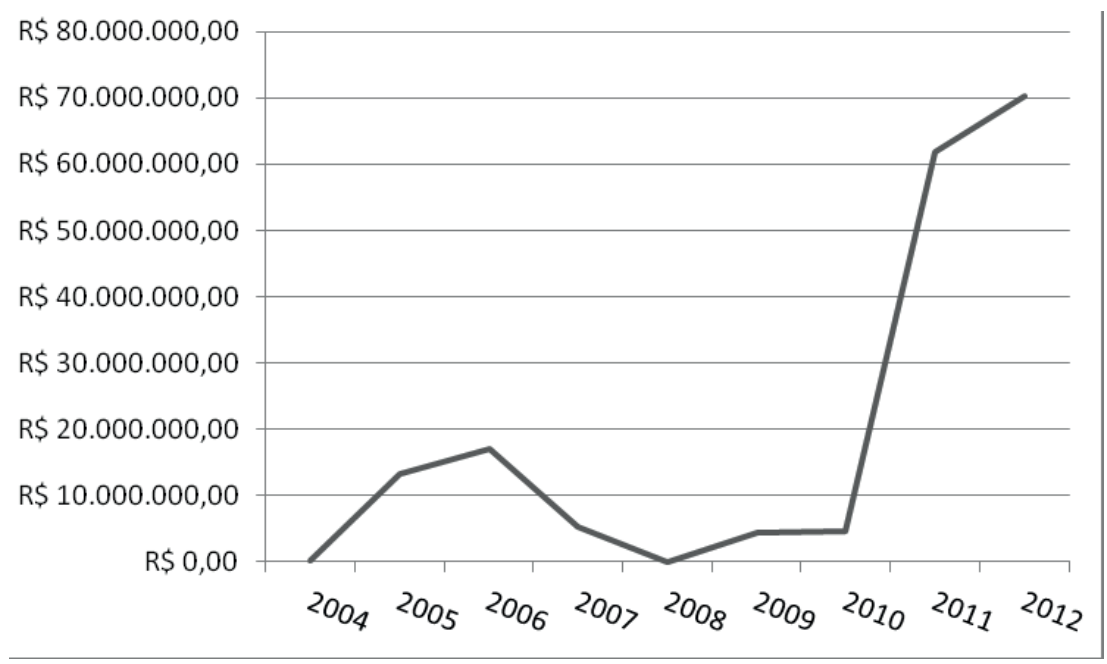

FIGURA 1 A Compensação Ambiental no Estado de Minas Gerais distribuída ao longo dos anos.

FIGURE 1 The Environmental Compensation in the State of Minas Gerais distributed over the years.

compensação ambiental a partir de 2004 quando o primeiro processo foi julgado. O Decreto Federal no 4.340/2002 regulamentou $\circ$ exerć́cio da competência legislativa concorrente dos estados, garantindo a legitimidade para legislar de maneira complementar.

No ano de 2008 houve paralização no julgamento dos processos de compensação ambiental em função da ADIn 3.379-6 que estava em tramitação para julgamento no STF; após a decisão em 2008 , os processos voltaram a ser julgados e ocorre um pequeno aumento no gráfico, como pode ser visualisado na figura abaixo.

Em 2009 aconteceu um fato marcante, que foi a publicação do Decreto Federal $n^{\circ} 6.848 / 2009$ com toda a metodologia para o cálculo da compensação ambiental, deixando de considerar a taxa de $0,5 \%$ como limite mínimo.

No ano de 201I houve uma mudança na direção do IEF e a equipe da UNESCO responsável pela aplicação do instrumento foi substituída por funcionários concursados do próprio órgão ambiental de MG. Neste período de transição os processos ficaram interrompidos a espera de um laudo técnico. A nova equipe responsável precisou de um período de treinamento para nova função, em virtude disto, houve um acúmulo de processos.

Atualmente a nova gerência tem efetuado ações denominadas de "Força-Tarefa", em que servidores de outras regionais são convocados para auxiliar na avaliação técnica dos laudos apresentados pelos empreendedores no processo de licenciamento. $O$ resultado pode ser observado no salto significativo a partir do ano de $201 \mathrm{l}$.

\section{CONCLUSÃO}

Acompensaçãoambiental paraempreendimentos causadores de significativo impacto ambiental foi consolidada no Brasil por meio da Lei $n^{\circ}$ 9.985/2000 (SNUC). A legislação avançou e representa importante montante financeiro para a tutela dos recursos naturais, especialmente das Unidades de Conservação.

No estado de Minas Gerais, este instrumento, em consonância com a legislação federal, gerou um montante financeiro representativo. Indica-se a necessidade do desenvolvimento de mais pesquisas para verificar os efeitos da efetividade da compensação ambiental aplicada nas Unidades de Conservação.

\section{AGRADECIMENTOS}

A Gerência de Compensação Ambiental/ IEF do estado de Minas Gerais; ao CNPq.

\section{REFERÊNCIAS}

ANTUNES, P. B. Direito ambiental.14. ed. Rio de Janeiro: Lumen Juris, 2012. $1192 \mathrm{p}$.

ANTUNeS, P. B. Política Nacional do Meio Ambiental PNMA: comentários à Lei 6.938, de 31 de agosto de 1981. Rio de Janeiro: Lumen Juris, 2005. 244 p.

BESSA, P. ADI - 3.378-6 DF - compensação ambiental. Disponível em: <http://www.oeco.com.br/paulobessa/I6948-adi--3378-6-df--compensacao-ambiental >. 
Acesso em: 20 maio 2012 .

BRASIL. Decreto no 4.340, de 22 de agosto de 2002. Regulamenta artigos da Lei $n \circ$ 9.985, de 18 de julho de 2000, que dispõe sobre o Sistema Nacional de Unidades de Conservação da Natureza - SNUC. Brasília, 2002. Disponível em: <http://www.planalto.gov.br/ccivil_03/ decreto/2002/d4340.htm >. Acesso em: 10 nov. 2012.

BRASIL. Decreto n $\mathbf{6 . 8 4 8}$, de 14 de maio de 2009. Altera e acrescenta dispositivos ao Decreto $n^{\circ} 4.340$, de 22 de agosto de 2002, para regulamentar a compensação ambiental. Brasília, 2009. Disponível em:<http://www. planalto.gov.br/ccivil_03/_Ato2007-2010/2009/Decreto/ D6848.htm >. Acesso em: I0 nov. 2012.

BRASIL. Lei $\mathbf{n}^{\circ}$ 12.651, de 25 de maio de 2012. Dispõe sobre a proteção da vegetação nativa. Brasília, 20I2. Disponível em:<http://www.planalto.gov.br/ccivil_03/_Ato20II 20I4/20I2/Lei/LI265I.htm >. Acesso em: 10 nov. 2012.

BRASIL. Lei $\mathbf{n}^{\circ} \mathbf{6 . 9 3 8}$, de 31 de agosto de 1981. Dispõe sobre a Política Nacional do Meio Ambiente, seus fins e mecanismos de formulação e aplicação. Brasília, 198I. Disponível em: <http:// www.planalto.gov.br/ccivil_03/leis/16938.htm>. Acesso em: 10 nov. 2012

BRASIL. Lei $\mathbf{n}^{\circ}$ 9.985, de 18 de julho de 2000. Regulamenta o art. 225, § Iำ, incisos I, II, III e VII da Constituição Federal, institui o Sistema Nacional de Unidades de Conservação da Natureza. Brasília, 2000. Disponível em:<http://www. planalto.gov.br/ccivil_03/leis/19985.htm>. Acesso em: 10 nov. 2012.

BRASIL. Lei $\mathbf{n}^{\circ}$ I I.428, de 22 de dezembro de 2006. Dispõe sobre a utilização e proteção da vegetação nativa do Bioma Mata Atlântica, e dá outras providências. Disponível em: <http://www.planalto.gov.br/ccivil_03/ato20042006/2006/lei/l11428 .htm >. Acesso em: 10 nov. 2012.

BRASIL. Lei Complementar $\mathbf{n}^{\circ}$ I40, de 8 de dezembro de 20II. Fixa normas, nos termos dos incisos III, VI e VII do caput e do parágrafo único do art. 23 da Constituição Federal, para a cooperação entre a União, os Estados, o Distrito Federal e os Municípios nas ações administrativas decorrentes do exercício da competência comum relativas à proteção das paisagens naturais notáveis, à proteção do meio ambiente, ao combate à poluição em qualquer de suas formas e à preservação das florestas, da fauna e da flora; e altera a Lei ${ }^{\circ} 6.938$, de 31 de agosto de 198I. Disponível em: <http://www.planalto.gov.br/ccivil_03/ leis/Icp/Lcp140.htm>. Acesso em: I0 nov. 2012.

BRASIL. Resolução CONAMA n $\mathbf{1 0}$, de 3 de dezembro de 1987. Brasília, 1987. Disponível em: <http://www.mma. gov.br/port/conama/legiabre.cfm?codlegi $=61>$. Acesso em: 10 nov. 2012 .
BRASIL. Resolução CONAMA n ${ }^{2}$, de 18 de abril de 1996. Brasília, 1996. Disponível em: <http://licenciamento. cetesb.sp.gov.br/legislacao/federal/resolucoes/1996_Res_ CONAMA_2.pdf >. Acesso em: 10 nov. 2012.

BRASIL. Métodos e técnicas de pesquisa social. 5. ed. São Paulo: Atlas, 1999. 206 p.

GIL, A. C. Como elaborar projetos de pesquisa. 4. ed. São Paulo: Atlas, 2002. 176 p.

IBAMA. Instituto Brasileiro do Meio Ambiente e dos Recursos Naturais Renováveis. Portaria $\mathbf{n}^{\circ} \mathbf{7}$, de 19 de janeiro de 2004. Criou a Câmara de Compensação Ambiental. Brasília, 2004. Disponível em: <http://www.ipef.br/legislacao>. Acesso em: 10 nov. 2012.

JUCOVSKY, V. L. R. S. Instrumentos jurídicos de participação da Sociedade na Proteção do Meio Ambiente no Brasil. In: FREITAS, V.P. Direito ambiental em evolução. Curitiba: Juruá, 20I0. p. 34I-357.

MACHADO, P. A. L. Direito ambiental brasileiro. 19. ed. São Paulo: Malheiros, 201 I. 1312 p.

MINAS GERAIS. Decreto $\mathbf{n}^{\circ} \mathbf{4 4 . 3 1 6}$, de 7 de junho de 2006. Dispõe sobre a Organização do Conselho Estadual De Política Ambiental - Copam, De Que Trata A Lei N 12.585 De 17 De Julho De 1997. Belo Horizonte, 2006. Disponível em:<http://www.lexml.gov.br/urn/urn:lex:br;minas. gerais:estadual:decreto:2006-06-07;44316>. Acesso em: 10 nov. 2012.

MINAS GERAIS. Decreto $\boldsymbol{n}^{\circ} \mathbf{4 5 . I 7 5}$, de 17 de setembro de 2009. Estabelece metodologia de gradação de impactos ambientais e procedimentos para fixação e aplicação da compensação ambiental. Belo Horizonte, 2009. Disponível em: <http://ws.mp.mg.gov.br/biblio/informa/l809I 2403. htm >. Acesso em: 10 nov. 2012.

MINAS GERAIS. Deliberação Normativa COPAM $\mathbf{n}^{\circ} \mathbf{7 4}$, de 9 de setembro de 2004. Conselho Estadual de Política Ambiental. Belo Horizonte, 2009. Disponível em: <http:// sisemanet.meioambiente.mg.gov.br/mbpo/recursos/ DeliberaNormativa74.pdf $>$. Acesso em: 10 nov. 2012.

PAULA, M. da G. La protección del medio ambiente en la Constituición Federal Brasilena de 1988. 2010. I0I p. Tesis (Doctorado en Derecho Ambiental) - Universidad de Barcelona, Barcelona, 2010.

SMETS, $H$. Le principe utilisateur-payeur pour la gestion durable des resouces naturelles. Lisboa: GEP/UPP, 1998. 